\title{
Optimized Oxidative Stress Protocols for Low-microliter Volumes of Mammalian Plasma Evan A. Langille ${ }^{1,2, *}$
}

\author{
${ }^{1}$ Department of Chemistry and Biology, Bishop's University, Sherbrooke, Canada; ${ }^{2}$ Department of \\ Chemistry, Memorial University of Newfoundland, St. John's, Canada \\ *For correspondence: ealangille@mun.ca
}

\begin{abstract}
[Abstract] Small blood volumes commonly obtained from small mammals during field studies are only sufficient for a single biochemical assay. In this study, we used blood collected from a population of wild eastern chipmunks (Tamias striatus) and developed modified methods to improve analytical selectivity and sensitivity required for measuring markers of oxidative stress using small blood volumes. Specifically, we proposed a modified malondialdehyde (MDA) analysis protocol by high performance liquid chromatography (HPLC) and also optimized both the uric acid independent ferric reducing antioxidant power (FRAP) and hypochlorous acid shock capacity (HASC) assays. We present methods in which a total volume of less than $60 \mu \mathrm{l}$ of plasma is required to obtain a comprehensive portrait of an individual's oxidative profile.
\end{abstract}

Keywords: High-performance liquid chromatography, Oxidative stress markers, Lipid peroxidation, Ferric reducing antioxidant power, Hypochlorous acid, Plasma assays, Low blood volume tests, Small mammal ecological studies, Antioxidants

[Background] Measuring markers of oxidative stress has become increasingly popular and useful for the evaluation of individual's physiological status. Measuring multiple oxidative stress markers and estimating methodological precision usually requires large blood sample volumes, making it difficult for researchers to perform comprehensive analyses of oxidative stress profile of small wild animals. We present in-house assays optimized to yield the most selective analysis for each marker using the smallest blood volumes possible (Langille et al., 2018).

MDA is a product of lipid peroxidation that in recent years has been measured by HPLC (Nussey et al., 2009). We present an HPLC method employing UV detection that uses a low volume of plasma to obtain a sensitivity and detection range appropriate for oxidative stress studies.

The ferric reducing antioxidant power (FRAP) assay has been extensively used in various disciplines ranging from agronomy and nutrition (Carlsen et al., 2010; Di Silvestro et al., 2017) to ecological studies (Griffin and Bhagooli, 2004; Ruykys et al., 2012; Eikenaar et al., 2018). Antioxidants in the samples reduce the ferric-tripyridyltriazine $\left(\mathrm{Fe}^{3+}-\mathrm{TPTZ}\right)$ complex to ferrous tripyridyltriazine $\left(\mathrm{Fe}^{2+}-\mathrm{TPTZ}\right)$, producing a blue color. The coloration intensity is proportional to the reducing capacity of the mostly non-enzymatic antioxidants in the plasma, hence providing the overall antioxidant capacity. Uric acid has been shown to interfere with the result of this assay however, Duplancic et al. (2011) proposed removing the uric acid using uricase with larger volume sample. We optimized the amount of uricase 
and sample needed to successfully remove all uric acid from a smaller sample, therefore improving the efficiency and accuracy of the test.

The HASC assay is commonly referred to by its kit named OXY-Adsorbent Test ${ }^{\mathrm{TM}}$ from Diacron International (Grosseto, Italy). In this test, an excess of hypochlorous acid, a strong oxidant, is added and incubated with a plasma sample. The hypochlorous acid oxidizes any reduced components in the plasma, then a chromogenic dye is added to quantify the remaining hypochlorous acid. Although the test was already optimized for $10 \mu \mathrm{l}$, the relatively high cost of each plate made it difficult for researchers to utilize this kit in large studies. We reduced the required volume to $1 \mu \mathrm{l}$ and provide an in-house protocol to prepare the reagents and execute the test.

\section{Materials and Reagents}

1. Standard flat bottomed 96-well plates (Sarstedt AG \& Co., catalog number: 82.1581)

2. Screw cap $500 \mu \mathrm{l}$ microcentrifuge tube (BioBasic, catalog number: TC132-SN)

3. $300 \mu \mathrm{l}$ microinsert HPLC vial (Chromatogaphic Specialties, catalog number: C73302101232)

4. $1.5 \mathrm{ml}$ microcentrifuge tubes (BioBasic, catalog number: BT620NS)

5. $15 \mathrm{ml}$ centrifuge tube (VWR, catalog number: 89401-568)

6. $50 \mathrm{ml}$ centrifuge tube (VWR, catalog number: 76176-956)

7. Aluminum Foil (Fisher, catalog number: 01-213-101)

8. Acetonitrile, HPLC grade (VWR, catalog number: CABDH83639.400)

9. Water, HPLC grade (VWR, catalog number: CABDH23595.400)

10. Trifluoroacetic acid, HPLC grade (VWR, catalog number: CATX1276-6)

11. 2-thiobarbituric acid (EMD Millipore, catalog number: 108180)

12. Malondialdehyde bis (diethylacetal) $\left(4^{\circ} \mathrm{C}, 12\right.$ months) (Sigma-Aldrich, catalog number: T9889)

13. Butylated hydroxytoluene (Sigma-Aldrich, catalog number: B1378)

14. Trichloroacetic acid $6.1 \mathrm{~N}$ (Sigma-Aldrich, catalog number: T0699)

15. Uricase $\left(-20^{\circ} \mathrm{C}, 12\right.$ months) (Sigma-Aldrich, catalog number: U0880)

16. Ferric Chloride Hexahydrate (BioBasic, catalog number: FD0201)

17. Ferrous Sulfate (BioBasic, catalog number: FB0461)

18. Sodium Acetate Trihydrate (BioBasic, catalog number: SB0481)

19. Acetic Acid, Glacial (VWR, catalog number: CA71006-424)

20. TPTZ (Sigma-Aldrich, catalog number: T1253)

21. NPD (Sigma-Aldrich, catalog number: 193992)

22. $12.5 \%$ Sodium Hypochlorite (store in the dark, 12 months) (VWR, catalog number: BDH7038$4 \mathrm{~L})$

23. Hydrochloric Acid ( $\mathrm{HCl})$ (VWR, catalog number: CA11020-884)

24. Sulfuric Acid (VWR, catalog number: CA11024-170)

25. Sodium Hydroxide ( $\mathrm{NaOH}$ ) (VWR, catalog number: BDH9292)

26. Anhydrous Ethanol (Commercial Alcohols, catalog number: P016EAAN) 
27. $0.1 \mathrm{M}$ butylated hydroxytoluene (BHT) solution (see Recipes)

28. $15 \%$ trichloroacetic acid solution (see Recipes)

29. $2 \mathrm{~N} \mathrm{NaOH}$ solution (see Recipes)

30. 2-thiobarbituric acid solution (see Recipes)

31. $0.25 \mathrm{M} \mathrm{HCl}$ solution (see Recipes)

32. Uricase stock solution (see Recipes)

33. Uricase working solution (see Recipes)

34. Acetate buffer solution (see Recipes)

35. $400 \mathrm{mM}$ stock $\mathrm{HCl}$ solution (see Recipes)

36. $40 \mathrm{mM} \mathrm{HCl}$ solution (see Recipes)

37. TPTZ solution (see Recipes)

38. Ferric chloride solution (see Recipes)

39. $30 \mathrm{mM}$ Ferrous sulfate stock solution (see Recipes)

40. FRAP reagent (see Recipes)

41. NPD stock solution (see Recipes)

42. 0.6 M Sulfuric acid solution (see Recipes)

43. Oxidant solution (see Recipes)

\section{Equipment}

1. $100 \mathrm{ml}$ volumetric flask, class A (VWR, catalog number: 10124-072)

2. $500 \mathrm{ml}$ volumetric flask, class $A$ (VWR, catalog number: 10545-998)

3. $1 \mathrm{~L}$ volumetric flask, class A (VWR, catalog number: 10546-000)

4. Amber bottles (VWR, catalog number: 89221-624)

5. Ice bath (VWR, catalog number: 10146-190)

6. Water bath (VWR, catalog number: 89501-464)

7. Fume hood (VWR, catalog number: 89260-062)

8. Magnetic stirrer (VWR, catalog number: 97042-634)

9. Analytical balance (VWR, catalog number: 10205-026)

10. iMark Filter absorbance microplate reader (Bio-Rad, catalog number: 1681135)

11. $515 \mathrm{~nm}$ Filter for microplate reader (Bio-Rad, catalog number: 1681033)

Note: If a $515 \mathrm{~nm}$ filter is not available, an alternative filter in the range of 510-520 nm will suffice.

12. 1100 Series Binary pump (Agilent Technologies, model: G1312A)

13. 1100 Series Autosampler (Agilent Technologies, model: G1313A)

14. 1100 Series Column compartment (Agilent Technologies, model: G1316A)

15. 1100 Series Variable wavelength detector (Agilent Technologies, model: G1315A)

16. ODS2 $250 \times 4.6 \mathrm{~mm} 5 \mu \mathrm{m}$ HPLC column (Waters Corp., catalog number: PSS831915)

17. Vortex Mixer (VWR, catalog number: 10153-842)

18. Shaking dry-block (Eppendorf, VWR, model: Thermomixer, catalog number: CA11028-280) 
19. Barnstead E-Pure water system (Barnstead, Thermo Fisher, model: E-Pure)

20. Refrigerated Centrifuge (Eppendorf, model: $5418 \mathrm{R}$ )

21. Micropipette set (Eppendorf, catalog number: 2231000601)

22. Spectrophotometer (Thermo Fisher, model: Genesys10S)

23. pH meter (VWR, catalog number: 89231-662)

24. $4{ }^{\circ} \mathrm{C}$ refrigerator (VWR, catalog number: 89239-070)

25. $-20^{\circ} \mathrm{C}$ freezer (VWR, catalog number: 10819-408)

26. $-80^{\circ} \mathrm{C}$ freezer (VWR, catalog number: 10160-740)

\section{$\underline{\text { Software }}$}

1. OpenLab Chromatography Data System (Agilent Technologies, www.agilent.com)

2. Microplate Manager 6 (Bio-Rad Laboratories Canada Ltd., www.biorad.com)

\section{Procedure}

A. MDA quantitation

Notes:

a. Field samples should be spun down in a hematocrit centrifuge directly after collection in order to store the plasma separately. We recommend transferring the separated plasma to a $0.5 \mathrm{ml}$ centrifuge tube for storage. See Langille et al., 2018 for more details on field sampling.

b. Store samples at $-80^{\circ} \mathrm{C}$ before analysis and test within one year of collection.

c. A single HPLC system and two workers can expect to process a calibration curve and about 2030 plasma samples in one working day.

1. Prepare the HPLC system using the parameters listed in Table 1.

Table 1. HPLC system parameters to be used in MDA quantification method

\begin{tabular}{|l|l|}
\hline Parameter & Setting \\
\hline Solvent A & Water with 0.1\% Trifluoroacetic acid (TFA) \\
\hline Solvent B & Acetonitrile \\
\hline xMobile Phase & $70: 30 \mathrm{~A}: \mathrm{B}$ Isocratic \\
\hline Flow Rate & $1 \mathrm{ml} / \mathrm{min}$ \\
\hline System Pressure & $165 \mathrm{Bar}$ \\
\hline Injection Volume & $20 \mu \mathrm{l}$ \\
\hline Column & $\mathrm{ODS} 250 \times 4.6 \mathrm{~mm} 5 \mu \mathrm{m}$ \\
\hline Column temperature & $30.0^{\circ} \mathrm{C}$ \\
\hline Wavelength & $532 \mathrm{~nm}$ \\
\hline Runtime & $4.00 \mathrm{~min}$ \\
\hline
\end{tabular}


2. Prepare a $1.00 \mathrm{mM}$ MDA working solution by adding $100 \mathrm{mM}$ 1,1,3,3-tetraethoxypropane stock solution to a $100 \mathrm{ml}$ volumetric flask, diluting to the mark with ultrapure water. Mix well.

3. Prepare an MDA calibration by serially diluting the freshly prepared $1.00 \mathrm{mM} \mathrm{1,1,3,3-}$ tetraethoxypropane working solution using micropipettes. Prepare fresh calibration curve before every batch of samples. See Table 2 .

Table 2. Preparation of serially diluted 1,1,3,3-tetraethoxypropane standards for the MDA quantification method

\begin{tabular}{|l|l|l|}
\hline Final Concentration $(\boldsymbol{\mu M})$ & Volume of previous $(\boldsymbol{\mu l})$ & Volume $\mathbf{d H}_{\mathbf{2}} \mathbf{O}(\boldsymbol{\mu l})$ \\
\hline 1,000 & $\mathrm{n} / \mathrm{a}$ & $\mathrm{n} / \mathrm{a}$ \\
\hline 20 & 30 & 1,470 \\
\hline 15 & 750 & 250 \\
\hline 10 & 400 & 200 \\
\hline 5 & 300 & 300 \\
\hline 2.5 & 300 & 300 \\
\hline 1.25 & 300 & 300 \\
\hline 0 (Blank) & 0 & 1,000 \\
\hline
\end{tabular}

4. Store standards on ice until use.

5. Thaw plasma samples on ice and spin for $1 \mathrm{~min}$ in a refrigerated centrifuge at 3,000 $\times g$ and $4^{\circ} \mathrm{C}$ to collect the plasma at the bottom of the tube.

6. Prepare standard $1.5 \mathrm{ml}$ microcentrifuge tubes with labels for the samples and the standards. Note: We prefer to run all in triplicate, so we purchased a label printer which can make the repeated labeling of tubes much easier.

7. Transfer $20 \mu \mathrm{l}$ of either standard or plasma sample to the labeled tubes.

8. Add $2 \mu$ l butylated hydroxytoluene (BHT) solution (see Recipes) and $5 \mu \mathrm{l}$ of $2 \mathrm{~N} \mathrm{NaOH}$ solution (see Recipes) to each tube.

9. Briefly vortex tubes, and then transfer to the shaking dry block incubator set at $60^{\circ} \mathrm{C}$ for $30 \mathrm{~min}$ and 400 rpm agitation.

10. Once this is finished, remove tubes to the ice bucket, and add $100 \mu \mathrm{l}$ of $15 \%$ trichloroacetic acid solution to precipitate proteins.

11. Briefly vortex the samples, then incubate in the ice bath for $5 \mathrm{~min}$.

12. Centrifuge the tubes for $10 \mathrm{~min}$ at $14,000 \times g$ and $4^{\circ} \mathrm{C}$ to pellet the protein.

13. Carefully, without disturbing the protein pellet, transfer $100 \mu$ l of supernatant to a $500 \mu \mathrm{l}$ screw cap microcentrifuge tube.

14. To that tube, also add $50 \mu \mathrm{l}$ of 2-thiobarbituric acid derivatizing solution (see Recipes).

15. Ensure the caps on the tubes are well sealed and place in a dry block incubator at $100{ }^{\circ} \mathrm{C}$ for 60 min.

16. Remove the tubes from the block into an ice bath, and when cooled, centrifuge for $5 \mathrm{~min}$ at 
$14,000 \times g$ and $4{ }^{\circ} \mathrm{C}$.

17. Transfer $60 \mu \mathrm{l}$ of the derivatized solution to the microinsert HPLC vial.

18. Transfer $5 \mu \mathrm{l}$ of the derivatized solution to the pooled QC vial, except for standards.

Note: The $Q C$ is a pooled sample of all the plasma you will process in one day. Injecting this QC throughout the HPLC run process (every 8-10 samples) will allow you to observe if there are any issues with the runs or decomposition of your samples.

19. Subject the vials to HPLC analysis in triplicate within $12 \mathrm{~h}$ of sample preparation.

B. FRAP assay

Notes:

a. Samples should be stored at $-80^{\circ} \mathrm{C}$ before analysis and thawed on ice.

b. FRAP reagent is light sensitive, and unstable in ambient air. The reagent must be prepared directly before use.

1. Prepare a working iron sulfate solution by diluting $1 \mathrm{ml}$ of the $300 \mathrm{mM}$ stock with $9 \mathrm{ml}$ of distilled water in a $15 \mathrm{ml}$ centrifuge tube. Use this $30 \mathrm{mM}$ solution to prepare the calibration solutions in $15 \mathrm{ml}$ centrifuge tubes (see Table 3).

Table 3. Dilution table of iron sulfate standards for the FRAP assay

\begin{tabular}{|l|l|l|}
\hline Final Concentration (mM) & Volume of previous $(\mathbf{m l})$ & Volume $\mathbf{d H}_{\mathbf{2}} \mathbf{O}(\mathbf{m l})$ \\
\hline 30 & n/a & n/a \\
\hline 3 & 1 & 9 \\
\hline 2 & 6.6 & 3.3 \\
\hline 1 & 5 & 5 \\
\hline 0.5 & 5 & 5 \\
\hline 0 (Blank) & 0 & 10 \\
\hline
\end{tabular}

2. Obtain a standard flat bottomed 96-well plate, and plan for where the position of the calibration curves and the samples will be positioned. We like to run 2 calibration curves per plate to account for errors.

3. Pipette a $5 \mu \mathrm{l}$ aliquot of either standard or sample into each well to be measured, followed by $5 \mu \mathrm{l}$ of ultrapure water containing uricase $(1.00 \mathrm{U} / \mathrm{ml}$, see Recipes). Be sure that the two drops mix well.

4. Incubate the solution for $5 \mathrm{~min}$ at room temperature on an orbital shaker at $100 \mathrm{rpm}$.

5. Add $200 \mu \mathrm{l}$ of FRAP reagent (see Recipes) to each well using a multichannel pipette.

6. Place the plate into the microplate reader and shake for $\mathbf{3 0}$ min on low speed, seen as "LO" on software.

7. After $30 \mathrm{~min}$, the absorbance at $595 \mathrm{~nm}$ is read vs. reagent blank. 


\section{HASC assay}

Notes:

a. Samples should be stored at $-80^{\circ} \mathrm{C}$ before analysis and thawed on ice.

b. Oxidant solution is unstable in air and should be prepared with care. Adjustment of the $\mathrm{pH}$ should be carried out in a fume hood as small quantities of chlorine gas will be produced.

1. Prepare the oxidant solution as in the Recipes section. Protect the solution from light by wrapping the bottle in aluminum foil, and work quickly with the solution.

2. From the oxidant solution, prepare a calibration curve of $\mathrm{HClO}$ by diluting the $1 \mathrm{x}$ to $2 \mathrm{x}, 4 \mathrm{x}, 8 \mathrm{x}$, $16 \mathrm{x}$ and $32 \mathrm{x}$ dilutions. Prepare $1 \mathrm{ml}$ of each solution.

3. To a standard 96-well flat bottom microplate, add $1 \mu \mathrm{l}$ plasma or standard and $100 \mu \mathrm{l}$ ultrapure water.

Note: We prefer to run at least two calibration curves per plate to account for any error which may occur.

4. Vortex the plate on a 2D shaker at $400 \mathrm{rpm}$ for $30 \mathrm{~s}$.

5. Using a multichannel pipette, add $100 \mu \mathrm{l}$ of oxidant solution to sample wells only. Note: Do not add oxidant solution to the standard wells. The standard is directly read as a serial dilution of HClO. Instead, add $100 \mu \mathrm{l}$ ultrapure water.

6. Shake the plate on an orbital shaker for $10 \mathrm{~min}$ at room temperature and $100 \mathrm{rpm}$.

7. Add $20 \mu \mathrm{l}$ of NPD solution (see Recipes) to each well of the plate.

8. Incubate the plate on an orbital shaker for $1 \mathrm{~min}$ at room temperature and $100 \mathrm{rpm}$.

9. Read the absorbance of the wells at $515 \mathrm{~nm}$.

\section{Data analysis}

1. MDA quantification

Area of the TBA $2-M D A$ adduct at $3.00 \mathrm{~min}$ is automatically integrated by the software. Export this data and use it to prepare the calibration curves and to quantify samples. Average triplicate data in its raw format then quantify using the standard linear calibration (see Langille et al., 2018).

2. FRAP assay

Export the absorbance data of the wells and take the average of the triplicate wells. Use this data to prepare the linear calibration and quantify samples (see Langille et al., 2018).

3. HASC assay

Export the absorbance data of the wells and take the average of the triplicate wells. Use this data to prepare the linear calibration and quantify samples (see Langille et al., 2018). 


\section{$\underline{\text { Notes }}$}

1. 2-Thiobarbituric acid is controlled under the controlled drugs and substances act (CDSA) in Canada and therefore a license is required to procure and possess this compound. An application had to be filed through Health Canada to obtain authorization to procure 2thiobarbituric acid. In the USA, 2-thiobarbituric acid is not controlled and can be purchased from Sigma-Aldrich.

2. It is important to note that micropipettes are used throughout this experiment and therefore investigators should be trained in good pipetting technique and be comfortable with the pipettes. It is crucial to practice good technique as very small volumes of solution are handled and therefore any error can be magnified if the pipette is not delivering an accurate volume.

3. All solutions should be prepared using good analytical techniques. If you plan to process a large number of samples for a single study, it is advisable to prepare the stocks once for that study to minimize variability between several preparations of the same solution.

4. The linear range of each UV detector or microplate reader can change depending on the model, age etc. It is important to check that the system provides a linear calibration before processing plasma samples.

5. The figures of merit to assess the performance of the method were calculated in the following ways: relative standard deviation (\%RSD) is the standard deviation divided by the mean of three separate preparations (and three injections per preparation) of the same sample. The limit of detection (LOD) and limit of quantification (LOQ) were calculated by measuring the noise of a blank injection. The LOD and LOQ are defined as 3 and 10 times the noise level of the blank, respectively.

6. The linearity of the MDA calibration curve from 1.25-20 $\mu \mathrm{M}$ was high using this method (\%RSD $=0.32, \mathrm{n}=7$ ). The LOD and LOQ were 0.06 and $0.125 \mu \mathrm{M}$ respectively. The inter-assay variation $(\% \mathrm{RSD}=9.31, \mathrm{n}=48)$ was representative of the laboratory measurement error. We obtained no significant increase for QC samples over time $\left(\beta=0.0195 \mu \mathrm{M}\right.$ per hour, $r^{2}=0.017$, $\mathrm{n}=8$ ). The $\mathrm{QC}$ quantifications compared to the mean of all the individuals assessed in each day revealed that there is little effect on the results from different days of analysis (slope $=0.99$, $r^{2}=0.98, n=9$ ). Example chromatograms are shown in Langille et al., 2018.

7. For the developed uric acid independent FRAP assay, the linearity of the calibration curve, from 0.5-3 $\mathrm{mM} \mathrm{FeSO}_{4}$, was high $(\% \mathrm{RSD}=2.50, \mathrm{n}=7)$. The inter-assay variation $(\% \mathrm{RSD})$ was 5.82 $(n=57)$.

8. The linearity of the calibration curve for the adapted HASC assay, ranging from $0.03-0.5 \mathrm{mM}$ $\mathrm{HClO}$, was high (\%RSD = 3.64, $n=4)$. The inter-assay variation (\%RSD) was $2.03(n=32)$.

9. If you are using a monochromator-based spectrophotometer or microplate reader, you can simply use the wavelengths suggested in this paper for measurement. 


\section{Recipes}

1. $0.1 \mathrm{M}$ butylated hydroxytoluene (BHT) solution

a. Dissolve $2.20 \mathrm{~g}$ butylated hydroxytoluene in $100 \mathrm{ml}$ anhydrous ethanol

b. The solution may require brief sonication to aid in rapid dissolution

c. Storage: RT, Shelf life: 3 months

2. $15 \%$ trichloroacetic acid solution

a. In a fume hood, add $15 \mathrm{ml} 6.1 \mathrm{~N}(100 \% \mathrm{w} / \mathrm{v})$ trichloroacetic acid solution slowly to $85 \mathrm{ml}$ ultrapure water

b. Briefly vortex to mix

c. Storage: RT, Shelf life: 3 months

3. $2 \mathrm{~N} \mathrm{NaOH}$ solution
a. Dissolve $8 \mathrm{~g} \mathrm{NaOH}$ pellets in $100 \mathrm{ml}$ ultrapure water
b. Stir with a magnetic stir plate until the pellets completely dissolve
c. Storage: RT, Shelf life: 3 months

4. 2-thiobarbituric acid solution
a. Dissolve $0.375 \mathrm{~g}$ 2-thiobarbituric acid in $100 \mathrm{ml} 0.25 \mathrm{M} \mathrm{HCl}$
b. Heat in a water bath at $50^{\circ} \mathrm{C}$ for $10 \mathrm{~min}$, then sonicate for $5 \mathrm{~min}$ to aid in rapid dissolution
c. Storage: $4{ }^{\circ} \mathrm{C}$, Shelf life: 3 months

5. $0.25 \mathrm{M} \mathrm{HCl}$ solution
a. In a fume hood, slowly add $10.4 \mathrm{ml} 12 \mathrm{M}$ (conc.) $\mathrm{HCl}$ to a $500 \mathrm{ml}$ volumetric flask, containing $300 \mathrm{ml}$ of ultrapure water
b. Swirl to mix and dilute to the mark
c. Storage: RT, Shelf life: 3 months

6. Uricase stock solution
a. Incubate $15 \mathrm{ml}$ of ultrapure water on ice to cool it before preparing the solution. Using the certificate of analysis provided with the uricase, calculate the mass needed to prepare a $1,000 \mathrm{U} / \mathrm{ml}$ stock
b. Using an analytical balance, carefully weigh the powder to the nearest $0.1 \mathrm{mg}$ on an analytical balance
c. Add $1 \mathrm{ml}$ pre-cooled water using a micropipette and dissolve by slowly pipetting the solution up and down. Do not vortex! Solutions of enzymes should never be vortexed
d. Storage: $-20^{\circ} \mathrm{C}$, Shelf life: 12 months

7. Uricase working solution
a. Dilute the Uricase stock solution by adding $1 \mu \mathrm{l}$ of the $1,000 \mathrm{U} / \mathrm{ml}$ to $999 \mu \mathrm{l}$ of pre-cooled ultrapure water using micropipettes
b. Do not vortex, mix by gently inverting the tube several times
c. Storage: on ice, Shelf life: prepare daily 
8. Acetate buffer solution

a. In a fume hood, add $500 \mathrm{ml}$ ultrapure water to a $1 \mathrm{~L}$ volumetric flask. Then slowly add $16 \mathrm{ml}$ glacial acetic acid, followed by $2.70 \mathrm{~g}$ sodium acetate trihydrate

b. Mix the solution using a magnetic stirrer and dilute to about $10 \mathrm{ml}$ below the mark on the flask

c. Check the $\mathrm{pH}$ using a benchtop $\mathrm{pH}$ meter that has been calibrated a $\mathrm{pH} 4$ and 7 . The $\mathrm{pH}$ should be 3.6. If the $\mathrm{pH}$ is higher than 3.6, acidify the solution by adding acetic acid dropwise. If the $\mathrm{pH}$ is lower than 3.6 , raise the $\mathrm{pH}$ by adding sodium acetate.

d. Storage: $4{ }^{\circ} \mathrm{C}$, Shelf life: 1 month

9. $400 \mathrm{mM}$ stock $\mathrm{HCl}$ solution

a. In a fume hood, slowly add $16.5 \mathrm{ml}$ concentrated $\mathrm{HCl}$ to a $500 \mathrm{ml}$ volumetric flask, containing $300 \mathrm{ml}$ of ultrapure water

b. Swirl to mix and dilute to the mark

c. Storage: RT, Shelf life: 6 months

10. $40 \mathrm{mM} \mathrm{HCl}$ solution

Combine $100 \mathrm{ml}$ of $400 \mathrm{mM}$ stock solution with $900 \mathrm{ml}$ ultrapure water Storage: RT, Shelf life: 1 week

11. TPTZ solution
a. In a $100 \mathrm{ml}$ volumetric flask, dissolve $0.3123 \mathrm{~g} \mathrm{TPTZ}$ in $100 \mathrm{ml}$ of $40 \mathrm{mM} \mathrm{HCl}$ as prepared above
b. The solution may need to be placed in a $50{ }^{\circ} \mathrm{C}$ water bath to aid in dissolution
C. Storage: $4^{\circ} \mathrm{C}$, Shelf life: 1 month

12. Ferric chloride solution
a. In a fume hood, add $500 \mathrm{ml}$ of $40 \mathrm{mM} \mathrm{HCl}$ to a $1 \mathrm{~L}$ volumetric flask, add $5.41 \mathrm{~g}$ of ferric chloride hexahydrate and stir on a magnetic stir plate until dissolved
b. Dilute the solution to the mark with $40 \mathrm{mM} \mathrm{HCl}$. The acid is required to prevent hydrolysis and precipitation of ferrous ions
c. The solution should be stored in amber bottles, for up to two months. If you notice a red- brown precipitate forming, you must dispose of the solution and prepare it again

13. $30 \mathrm{mM}$ Ferrous sulfate stock solution

Dissolve $0.834 \mathrm{~g}$ ferrous sulfate heptahydrate in $100 \mathrm{ml}$ ultrapure water Storage: $4^{\circ} \mathrm{C}$, Shelf life: 1 month

14. FRAP reagent

a. Combine the following directly before use in a $50 \mathrm{ml}$ centrifuge tube on ice:

$20 \mathrm{ml}$ Acetate buffer

$2 \mathrm{ml}$ TPTZ sol'n

$2 \mathrm{ml} \mathrm{FeCl} 3 \mathrm{sol}^{\prime} \mathrm{n}$

$2.4 \mathrm{ml} \mathrm{dH}_{2} \mathrm{O}$ 
b. Mix reagents by vortexing. Solution should be straw in colour, if it is blue in colour, discard and prepare again

c. Storage: ice bath, Shelf life: $1-2 \mathrm{~h}$

15. NPD stock solution

a. Pipette $83 \mu \mathrm{l}$ of the pure NPD into a $50 \mathrm{ml}$ centrifuge tube containing $50 \mathrm{ml}$ of anhydrous ethanol

b. Wrap the tube in foil to protect from light. Mix using vortex mixer

c. Storage: $4{ }^{\circ} \mathrm{C}$, Shelf life: 3 months

16. $0.6 \mathrm{M}$ Sulfuric acid solution

a. In a fume hood, add $16.6 \mathrm{ml}$ conc. sulfuric acid slowly to a volumetric flask filled with $\mathrm{ml}$ of ultrapure water

b. Dilute to the mark and mix by inversion

c. Storage: RT, Shelf life: 3 months

17. Oxidant solution

a. Turn on the spectrophotometer and allow the lamp to warm for 30 min prior to starting. In a fume hood, add $1 \mathrm{ml}$ 10\% sodium hypochlorite to a $500 \mathrm{ml}$ volumetric flask containing $300 \mathrm{ml}$ of ultrapure water

b. Dilute to the mark and mix by inversion

c. Transfer $100 \mathrm{ml}$ of this solution to a $250 \mathrm{ml}$ media bottle and insert a pH probe that has been calibrated at $\mathrm{pH} 4$ and 7 . With moderate magnetic stirring, carefully add $0.6 \mathrm{M}$ sulfuric acid solution until the $\mathrm{pH}$ reaches 6.2

d. Using a quartz cuvette with a $1 \mathrm{~cm}$ pathlength, take the absorbance of the resultant solution vs. the absorbance of a water blank at $292 \mathrm{~nm}$

e. Apply the Beer-Lambert Law using the formula below:

$$
A=\varepsilon \times l \times c
$$

where, the molar absorptivity coefficient $(\varepsilon)$ of $\mathrm{HClO}$ is $350 \mathrm{~L} \mathrm{~mol}^{-1} \mathrm{~cm}^{-1}$, the pathlength (I) of the cell is $1 \mathrm{~cm}$ and the absorbance (A) is read at $292 \mathrm{~nm}$. The concentration (c) of $\mathrm{HClO}$ can then be solved for.

\section{Acknowledgments}

I am grateful to Patrick Bergeron, Vincent Lemieux, Dany Garant and Denis Réale for the sample collection in the field. This research was funded by Natural Sciences and Engineering Research Council of Canada (NSERC) discovery grants to PB and DG and Québec Center for Biodiversity Science (QCBS) seed grants to PB and DG. VL was supported by a scholarship from Fonds de Recherche du Québec-Nature et Technologies (FRQNT). 


\section{Competing interests}

The authors have declared that no competing interests exist.

\section{Ethics}

Ethics approval was obtained from both The Canadian Council on Animal Care (\#A2016-01Bishop's University) and the Ministère des Ressources naturelles et de la Faune du Québec (\#201705-01-102-05-S-F).

\section{References}

1. Carlsen, M. H., Halvorsen, B. L., Holte, K., Bohn, S. K., Dragland, S., Sampson, L., Willey, C., Senoo, H., Umezono, Y., Sanada, C., Barikmo, I., Berhe, N., Willett, W. C., Phillips, K. M., Jacobs, D. R., Jr. and Blomhoff, R. (2010). The total antioxidant content of more than 3100 foods, beverages, spices, herbs and supplements used worldwide. Nutr J 9: 3.

2. Di Silvestro, R., Di Loreto, A., Bosi, S., Bregola, V., Marotti, I., Benedettelli, S., Segura-Carretero, A. and Dinelli, G. (2017). Environment and genotype effects on antioxidant properties of organically grown wheat varieties: a 3-year study. J Sci Food Agric 97(2): 641-649.

3. Duplancic, D., Kukoc-Modun, L., Modun, D. and Radic, N. (2011). Simple and rapid method for the determination of uric acid-independent antioxidant capacity. Molecules 16(8): 7058-7068.

4. Eikenaar, C., Isaksson, C. and Hegemann, A. (2018). A hidden cost of migration? Innate immune function versus antioxidant defense. Ecol Evol 8(5): 2721-2728.

5. Griffin, S. and Bhagooli, R. (2004). Measuring antioxidant potential in corals using the FRAP assay. J Exp Mar Biol Ecol 302: 201-211.

6. Langille, E., Lemieux, V., Garant, D. and Bergeron, P. (2018). Development of small blood volume assays for the measurement of oxidative stress markers in mammals. PLoS One 13(12): e0209802.

7. Nussey, D. H., Pemberton, J. M., Pilkington, J. G. and Blount, J. D. (2009). Life history correlates of oxidative damage in a free-living mammal population. Funct Ecol 23: 809-817.

8. Ruykys, L., Rich, B. and McCarthy, P. (2012). Haematology and biochemistry of warru (Petrogale lateralis MacDonnell Ranges race) in captivity and the wild. Aust Vet J 90(9): 331340. 